\title{
Open
}

\section{Genetic counseling for women referred for advanced maternal age: a telegenetic approach}

To the Editor: Medical genetics and genetic counseling represent vital tools for communicating with patients about genetic risk, reproductive options, prenatal testing, and novel therapies. Medical geneticists and genetic counselors are the professionals in charge of genetic diagnosis and risk evaluation, representing the most important resource for communicating to patients all issues related to genetic diseases (both rare and common). There is a general consensus, promoted by the Eurogentest Network of Excellence (http://www.eurogentest.org), that genetic counseling should be a mandatory accompaniment to all medical genetics interventions. This becomes particularly relevant with the advent of high-throughput diagnosis, including noninvasive prenatal testing. Indeed, despite the potential for rapid results, the need for counseling delivered by expert geneticists must not be overlooked, and the issues surrounding data filtering and validation need to be addressed. This entails providing access to genetic counseling at various points within the health-care system, which will inevitably impact both national and local policy making. In the current economic climate, the medical geneticist is a relatively marginal figure, often restricted to a few specialist centers, even in countries of the European Union. Patients who are affected by rare diseases have the right to benefit from expert assistance in their clinical management, diagnosis, and care, no matter where they are or the rareness of their disease. Through the adoption of telemedical technology in genetics (telegenetics), as encouraged by various EU initiatives, the gap between specialists and patients may more easily be bridged. Multimedia telegenetics tools will enable us to provide interactive genetic consultations from a distance-feasibly to people in other countries-thereby increasing the accessibility of this invaluable service and helping to meet the needs of centers of excellence for rare diseases.

According to the World Health Organization, telemedicine is "the delivery of health-care services, where distance is a critical factor, by all health-care professionals using information and communication technologies for the exchange of valid information for diagnosis, treatment and prevention of disease and injuries, research and evaluation, and for the continuing education of health care providers, all in the interests of advancing the health of individuals and their communities." With this in mind, we produced a short digital film on telegenetic counseling for pregnant women of advanced maternal age. Reasoning that the increasing number of women and couples requiring genetic testing, many of whom will not have easy access to counseling centers, need a standardized, reliable approach, we explain the genetic risks associated with advanced maternal age, as well as possible preventive measures, prenatal testing procedures (both invasive and noninvasive), laboratory assessment methods (stating the specificity and accuracy of the available tests), and best-practice communication of results. We also explain any possible causes of test failure and stress the role of the medical geneticist and the importance of effective communication during genetic counseling. This video is freely available in both English and Italian (www.ospfe.it/geneticamedica). It is our hope that this initiative will facilitate communication among geneticists, obstetricians, pregnant women, and all stakeholders involved in prenatal care and diagnosis.

\section{ACKNOWLEDGMENT}

The SIGN project (Slovenian-Italian Genetic Network, http://www. signgenetics.eu) is acknowledged.

\section{DISCLOSURE}

The authors declare no conflict of interest.

Francesca Gualandi, $M D, P h D^{1,2}$, Stefania Bigoni, $M D^{1,2}$, Loredana Melchiorri, $P h D^{1,2}$, Barbara Buldrini, $P h D^{1,2}$, Alessandra Balboni, $P h D^{1,2}$, Marcella Neri, $M D^{1,2}$, Annarita Armaroli, $M D^{1,2}$, Giulia Parmeggiani, $M D^{1,2}$, Eleonora Italyankina, $M D^{1,2}$, Antonio Mauro, $M D^{1,2}$, Anna Ravani, PhD ${ }^{1,2}$, Sergio Fini, $M D^{1,2}$, Stefano Caracciolo, $M D^{3}$ and Alessandra Ferlini, $M D, P h D^{1,2}$

${ }^{1}$ Section of Medical Genetics and Microbiology, Department of Medical Sciences, University of Ferrara, Ferrara, Italy; ${ }^{2}$ Medical Genetics Unit, Department of Reproduction and Growth, S. Anna University Hospital, Ferrara, Italy; ${ }^{3}$ Section of General and Clinical Psychology, Department of Experimental and Clinical Medicine, University of Ferrara, Ferrara, Italy. Correspondence: Alessandra Ferlini (fla@unife.it)

\section{REFERENCE}

1. WHO. A Health Telematics Policy in Support of WHO's Health-For-All Strategy for Global Health Development: Report of the WHO Group Consultation on Health Telematics, 11-16 December 1997. Geneva, Switzerland: World Health Organization, 1998

doi:10.1038/gim.2014.103

This work is licensed under a Creative Commons Attribution-NonCommercial-NoDerivs 3.0

Unported License. The images or other third party material in this article are included in the article's Creative Commons license, unless indicated otherwise in the credit line; if the material is not included under the Creative Commons license, users will need to obtain permission from the license holder to reproduce the material. To view a copy of this license, visit http://creativecommons.org/licenses/by-nc-nd/3.0/ 